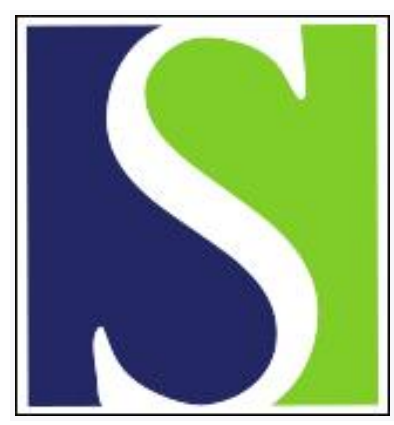

Scand J Work Environ Health 1976;2(3):185-189

https://doi.org/10.5271/sjweh.2807

Issue date: Sep 1976

A method for determining benzo(a)pyrene in air samples collected on glass fiber filters in occupational areas.

by Sollenberg J

Key terms: air sample; analysis; benzo(a)pyrene; determination; glass fiber; glass fiber filter; occupational area; polycyclic aromatic hydrocarbon; workroom air

This article in PubMed: www.ncbi.nlm.nih.gov/pubmed/973130

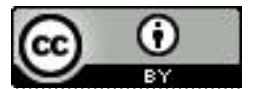




\title{
A method for determining benzo(a)pyrene in air samples collected on glass fiber filters in occupational areas
}

\author{
by JAN SOLLENBERG, Ph.D.1
}

\begin{abstract}
SOLLENBERG, J. A method for determining benzo(a)pyrene in air samples collected on glass fiber filters in occupational areas. Scand. $j$. work environ. \& health 3 (1976) 185-189. Benzo(a)pyrene was analyzed in air samples collected on glass fiber filters in occupational areas. Vacuum sublimation, thin-layer chromatography on acetylated cellulose, and fluorescence scanning of the thin-layer plate were performed. The recovery of the method was estimated by an isotope dilution technique using ${ }^{3} \mathrm{H}$-benzo(a)pyrene. Special equipment was constructed for sublimation. The detection limit for authentic samples was found to be about 10 pmoles per filter.
\end{abstract}

Key words: benzo(a)pyrene, polycyclic aromatic hydrocarbons, analysis, determination, workroom air.

The increasing pollution of air by polycyclic aromatic hydrocarbons, produced mainly by incomplete combustion, has been met by a great number of suggestions as to analytical methods. Of these hydrocarbons, many of which are carcinogenic, one of the most potent and most common is benzo(a)pyrene. This substance is stable, is relatively easy to separate and measure, and is therefore often taken as an indicator of the danger posed by air polluted with similar hydrocarbons.

As the volatility of benzo(a)pyrene is very low, the substance is found in air, not in the gaseous state, but absorbed on particles. When polluted air for the analysis of benzo(a)pyrene is sampled, particles are collected on glass fiber filters.

1 Chemical Division, Occupational Health Department, National Board of Occupational Safety and Health, Stockholm, Sweden.

Reprint requests to: Dr. Jan Sollenberg, Arbetarskyddsstyrelsen, Fack, S-10026 Stockholm, Sweden.
Most hitherto described procedures for the analysis of benzo(a)pyrene consist of the following three steps: separation from the filter, separation from other substances, and quantitation. The first step can be gas-phase extraction, organic solvent extraction, or sublimation $(1,5,6)$. Thin-layer, paper, or column chromatography has been used in the second step, followed by ultraviolet or fluorimetric determination (6). The second and third steps can be combined as in gas chromatography or high pressure liquid chromatography (4). With a special fluorescence spectrophotometric technique the second step can be omitted (3).

Schultz et al. have described a method for determining benzo(a)pyrene in ambient air using vacuum sublimation, thin-layer chromatography, and fluorimetry (8). In the present investigation a similar method is used. Special equipment was constructed for the sublimation step. Isotope dilution technique with ${ }^{3} \mathrm{H}$-benzo(a)pyrene of high specific activity was used for the estima- 
tion of the recovery. In most methods described the recovery is not considered. Radioactive tracers have very seldom been used (9). The present method is suitable for air samples from occupational environments in which the amount of benzo(a)pyrene ranges from a few pmoles or less per cubic meter of air (e.g., motor vehicle exhaust) to above $1 \mu \mathrm{mole} / \mathrm{m}^{3}$ (e.g., coal tar pitch fumes). Samples are taken with portable as well as stationary pumps. Less than $1 \mathrm{~m}^{3}$ of air passes through the filter.

\section{MATERIAL AND METHODS}

Benzo(a)pyrene was obtained from KochLight, England, and [G- $\left.{ }^{3} \mathrm{H}\right]$ benzo(a)pyrene $(25 \mathrm{Ci} / \mathrm{mmole}$ ) from the Radiochemical Centre, Amersham, England. All stock solutions of benzo(a)pyrene were made in cyclohexane. The concentration was spectrophotometrically determined, cyclohexane was replaced by ethanol, and $27,500 \mathrm{~cm}^{-1} \mathrm{M}^{-1}$ at $384 \mathrm{~nm}$ was used as the molar absorptivity (2). As benzo(a)pyrene is decomposed by light, all manipulations were performed under slight artifical illumination in the absence of sunlight.

The glass fiber filters were Munktell 3A-1 (Grycksbo, Sweden); diameter, $37 \mathrm{~mm}$.

The vacuum sublimation apparatus is shown in fig. 1. It consists of a test tube, a condenser ( $1 \mathrm{~mm}$ inner diameter of capillary), and a receiver. The apparatus was made by a local glassblower according to instructions. The filter to be analyzed was put in the test tube; $200 \mu 1$ $(18 \mathrm{nCi})$ of ${ }^{3} \mathrm{H}$-benzo(a)pyrene solution in cyclohexane was spread over the sample surface and left to dry. After the apparatus was assembled, vacuum $(1-10 \mathrm{~Pa})$ was achieved by a rotary-type vacuum pump. The test tube end was then inserted in a metal block thermostat, maintained at $300^{\circ} \mathrm{C}$, and left for $1 \mathrm{~h}$. The metal block thermostat is capable of sublimating five samples simultaneously. It was made by Liebisch, Brackwede, W. Germany, according to instructions. After the vacuum was released and the apparatus cooled, the test tube was removed, the apparatus was turned upside down, and cyclohexane $(5 \mathrm{ml})$ was introduced into the condenser. If the condensate had

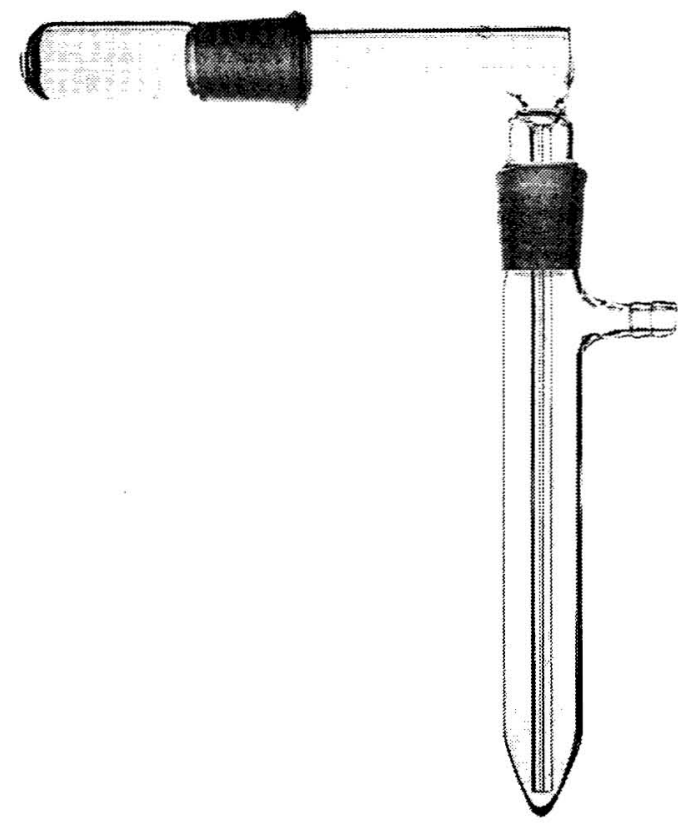

Fig. 1. Vacuum sublimation apparatus consisting of a test tube, condenser, and receiver.

dissolved incompletely in cyclohexane, acetone was added since it usually increases solubility. When the condensate had dissolved, the solution was allowed to run into the receiver. The condenser was removed and the solution was evaporated to dryness. The residue was dissolved in a minimal amount of cyclohexane $(\geq 20$ $\mu 1)$ or cyclohexane:acetone $(2: 1)$, and $2 \mu \mathrm{l}$ aliquots were taken out for thin-layer chromatography and liquid scintillation counting. The scintillation solution was Omnifluor (New England Nuclear, U.S.A.) in toluene $(4 \mathrm{~g} / 1)$. The counting was carried out in a Packard Tri-Carb Liquid Scintillation Spectrometer.

Thin-layer chromatography was performed according to Schaad (7). Precoated thin layers of $30 \%$ acetylated cellulose, $0.1 \mathrm{~mm}, 20 \times 20 \mathrm{~cm}$ (Polygram, MachereyNagel \& Co., Düren, W. Germany) were developed in ethanol:dichloromethane: water $(20: 10: 1)$. On each plate three references and two spots from each of two samples were run. The running distance was $15 \mathrm{~cm}(2 \mathrm{~h})$. The fluorimetric determination of benzo(a)pyrene was made directly on the thin-layer plate by means of a CAMAG-Z-scanner attached to a Zeiss 
PMQ-II spectrophotometer adapted to fluorimetric measurements. The excitation wavelength was $366 \mathrm{~nm}$, and emitted light at $407 \mathrm{~nm}$ was recorded. The scanning was made in the running direction of each sample, and the benzo(a)pyrene peak of unknowns was identified in a comparison of the coordinates on the plate with the reference spots. The calculation of the amount of benzo(a)pyrene was made from the peak areas, and every thin-layer plate was treated as a separate assay. The recovery was estimated in a comparison of the amount of ${ }^{3} \mathrm{H}$-benzo(a)pyrene added on the glass fiber filter with the radioactivity of an aliquot of the solution of the condensate. Correction for the addition of the radioactive compound in the fluorimetric determination was not necessary as the amount was far below the detection limit.

\section{RESULTS}

For the study of the recovery in the vacuum sublimation step, known amounts of benzo(a)pyrene were applied to clean

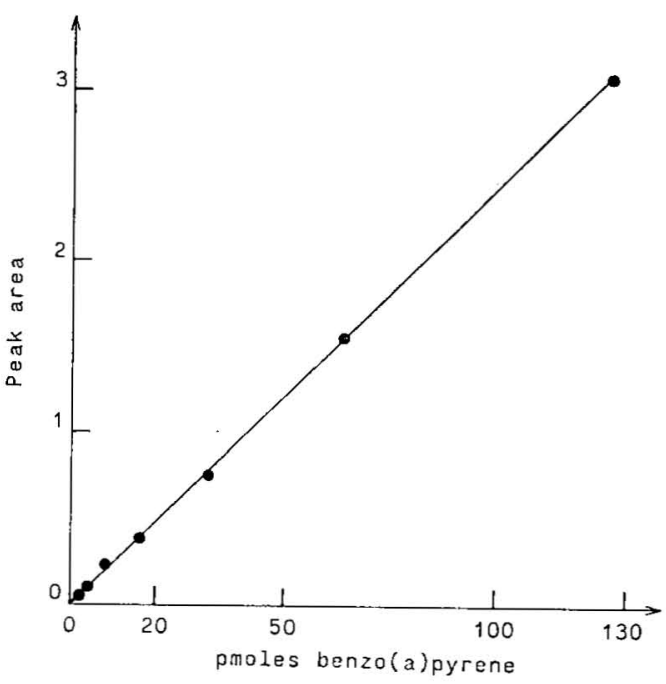

Fig. 2. Standard curve: Known amounts of benzo(a)pyrene were chromatographed on a thin-layer plate which was scanned fluorimetrically. The areas of the peaks obtained on the recorder are shown in arbitrary units versus the corresponding amounts given as pmoles of benzo(a)pyrene per spot. glass fiber filters. The filters were treated in the sublimation apparatus, and the recovery in the receiver was measured by absorption spectrophotometry. When three samples with 80 nmoles were tested, the recoveries were 100,102 , and $103 \%$, respectively. When ${ }^{3} \mathrm{H}-$ labelled benzo(a)pyrene with varying amounts of carrier was used, much smaller amounts could be detected. However, the recoveries were good even with very small amounts of benzo(a)pyrene applied on the filters. In two experiments with 24 pmoles, the recovery was 95.4 and $97.0 \%$, and with 0.8 pmole it was 91.0 and $93.8 \%$. Other types of glass fiber filters were tested. With filters containing an inorganic binder, a considerable loss of radioactivity or decrease in absorbance was found, probably because of the catalytic breakdown of benzo(a)pyrene. In an experiment with 46 nmoles applied on such a filter, the absorbance decreased by $43 \%$, but only $4.5 \%$ of the radioactivity was recovered, and $12.5 \%$ of the radioactivity remained on the filter.

Another recovery test was made which compared the same types of filters, but the samples were collected from different types of occupational areas. Once again the recoveries were excellent as determined by the measurement of radioactivity. However, a reduction in recovery sometimes appeared, especially in samples from iron mines containing small amounts of benzo(a)pyrene from diesel engine exhaust.

The scanning of the thin-layer plates was performed in the running direction of the samples although scanning at right angles to them gave comparable results with standard solutions. With authentic samples a more accurate estimation of the benzo(a)pyrene peak was obtained when scanning was done in the running direction.

A standard curve is shown in fig. 2. Up to 1 nmole per spot can be measured with good linearity. With more substance per spot the fluorimetric response declines relatively. For an estimation of the standard deviation of the fluorimetric determination, standard solutions of benzo(a)pyrene were applied on thin-layer plates with one concentration in seven spots on each plate. This was found to be $\pm 13 \%$ for 2.4 pmoles, $\pm 7 \%$ for 9.1 
pmoles, and $\pm 5 \%$ for 46.4 pmoles. The detection limit for authentic samples was found to be 10 pmoles per filter.

The purity of benzo(a)pyrene in the spot on the developed thin-layer plate from samples from various occupational sources was checked from a recording of a fluorescence (emission) spectrum. The recording can be made directly on the thin-layer plate or in a solution from the eluted spot. Fluorescence spectra from samples from an iron mine, steel works, foundry, and a plant manufacturing graphite electrodes were compared with the spectrum of pure benzo(a)pyrene. No difference due to fluorescence from contaminating substances was noted. Strong interference disturbed the spectrum in samples containing tobacco smoke. In such cases a second development of the thin-layer plate usually divided the peak first obtained into two, one of which was benzo(a)pyrene.

\section{DISCUSSION}

The primary objective of this work was to find a method for analyzing benzo(a)pyrene in dust samples collected on glass fiber filters in various occupational areas. The method should be suited to routine analysis of great amounts of samples but still be accurate and sensitive. The vacuum sublimation technique was preferred to extraction with a solvent because much better recovery and reproducibility is thereby permitted. The time of treatment is also considerably less, 1 and $6 \mathrm{~h}$, respectively, per sample. In previously described sublimation methods cool finger or capillary equipment has been used. We found these inconvenient for samples emitting much condensate. The apparatus constructed for this investigation was found more satisfactory in this respect as well. Other advantages are greater ease in dissolving the condensate, evaporating the solvent, and storing the sample, which can be done in the receiver of the apparatus. The addition of the isotope dilution step makes it possible to detect and to make corrections for losses in the analysis. Although the recovery of the method with standards is excellent, experience with authentic samples shows that varying recoveries appear.
The combination of thin-layer chromatography and fluorimetric scanning is more sensitive and less time-consuming than other methods used to determine benzo(a)pyrene. Other advantages are that thinlayer plates, once developed, can be scanned repeatedly and stored before scanning. One thin-layer plate containing various amounts of benzo(a)pyrene standards was stored in a dry and dark compartment. The scanning was repeated after 8 months, and the same results were obtained. A conception of the purity of the benzo(a)pyrene determined is also provided by a recording of the fluorescence spectrum directly from the spot on the thin-layer plate.

\section{ACKNOWLEDGMENT}

The author is very grateful to Agneta Arvidson, head-engineer, for excellent technical assistance.

\section{REFERENCES}

1. BURCHFIELD, H. P., GREEN, E. E., WHEELER, R. J. and BILLEDEAU, S. M. Recent advances in the gas and liquid chromatography of fluorescent compounds: I. A direct gas-phase isolation and injection system for the analysis of polynuclear arenes in air particulates by gas-liquid chromatography. J. chromatogr. 99 (1974) 697.

2. CLAR, E. Polycyclic hydrocarbons (vol. II). Academic Press, London 1964. p. 130.

3. HEINRICH, G. and GÜSTEN, H. Fluoreszenzspektroskopische Bestimmung kanzerogener polycyclischer Kohlenwasserstoffe in der Atmosphäre. Kernforschungszentrum Karlsruhe (Ber.) KFK 1975 UF, p. 77.

4. KLIMISCH, H.-J. Separation of polycyclic aromatic hydrocarbons by high-pressure liquid chromatography: Selective separation system for the quantitative determination of isomeric benz-pyrenes and of coronene. J. chromatogr 83 (1973) 11.

5. SAKABE, H., MATSUSHITA, H., HAYASHI, H., NOZAKI, K. and SUZUKI, Y. Mineral components and 3,4-benzpyrene in air pollutants of Tokyo. Ind. health. 3 (1965) 126.

6. SAWICKI, E., STANLEY, T. W., ELBERT, W. C., MEEKER, J. and MC PHERSON, S. Comparison of methods for the determination of benzo(a)pyrene in particulates 
from urban and other atmospheres. Atmos. environ. 1 (1967) 131.

7. SCHAAD, R. E. Thin-layer chromatographic separation of some polynuclear hydrocarbons. Microchem. $j .15$ (1970) 208.

8. SCHULTZ, M. J., ORHEIM, R. M. and BOVEE, H. H. Simplified method for the determination of benzo(a)pyrene in am-

Received for publication: 1976-01-17 bient air. Am. ind. hyg. assoc. j. 34 (1973) 404.

9. DE WIEST, F., RONDIA, D. and DELLA FIORENTINA, H.. Dosage du benzo(a)pyrène atmosphérique par couplage des techniques fluorimétrique et spectrophotométrique à scintillation liquide. J. chromatogr. 104 (1975) 399. 